\title{
Severity of primary open-angle glaucoma in patients with hypertension and diabetes
}

This article was published in the following Dove Press journal: Diabetes, Metabolic Syndrome and Obesity:Targets and Therapy

\author{
Anadi Khatri' \\ Jeevan Kumar Shrestha ${ }^{2}$ \\ Madhu Thapa ${ }^{2}$ \\ Bal Kumar Khatri ${ }^{3}$ \\ Muna Kharel ${ }^{3}$ \\ 'Department of Ophthalmology, \\ Vitreo-Retina Fellow, Lumbini Eye \\ Institute, Siddharthanagar, Nepal, \\ ${ }^{2}$ Department of Ophthalmology, B. P. \\ Koirala Lions Centre for Ophthalmic \\ Studies, Institute of Medicine, \\ Tribhuvan University Maharajgunj, \\ Kathmandu, Nepal, ${ }^{3}$ Birat Eye Hospital, \\ Biratnagar, Nepal
}

Background: Primary open-angle glaucoma (POAG) is a progressive optic neuropathy with numerous risk factors. Its severity with associated risk factors remains a widely debated topic. Aim: To evaluate the severity of POAG in patients with hypertension (HTN) and diabetes or both. Patients and methods: This hospital-based, cross-sectional descriptive study was conducted for a period of 18 months from January 2016 to June 2017. Diagnosed cases of POAG were evaluated for severity with associated risk factors.

Results: A total of 221 patients were enrolled in the study. The mean age of the patients was 54.4 ( $\mathrm{SD} \pm 15.9$ ) years with a male to female ratio of $0.93: 1$. Of the 221 patients, $68(31 \%)$ had a family history of POAG. Mean intraocular pressure was $15.8 \pm 4.87 \mathrm{mmHg}$, and mean central corneal thickness was $535.4 \pm 34.9 \mu \mathrm{m}$. A total of $81(36 \%)$ patients had HTN, $21(9.50 \%)$ had diabetes mellitus (DM), and 15 (6.80\%) had both HTN and DM. Analysis using SPSS version 20 was done. The severity of POAG was found to be significantly higher in patients with HTN, $\mathrm{DM}$, or both when evaluated on the basis of anatomical and functional loss.

Conclusion: POAG patients with HTN, DM, or both were found to have more severe POAG. Patients with these risk factors could represent "high-risk patients" with POAG. Patients with HTN and DM, or both may require evaluations on a more frequent basis to access the progression/severity of POAG.

Keywords: glaucoma in Nepal, POAG in Nepal, severity of POAG, hypertension, diabetes, systemic disorders in POAG

\section{Background}

Glaucoma is the second most common cause of blindness worldwide. ${ }^{1}$ It is a major global issue, causing significant ocular morbidity and disability due to its progressive nature resulting in an irreversible visual loss. ${ }^{2}$ Due to its chronicity, it is often also dubbed as a "silent killer" of the eye. Patients are usually asymptomatic until very advanced stage, making visual loss irrecoverable by the time they present to an ophthalmologist. ${ }^{3,4}$

One of its variant and the most common form - primary open-angle glaucoma (POAG) is a chronic, progressive, and anterior optic neuropathy that is associated with characteristic cupping and atrophy of the optic disc, visual field loss, open angles, and no obvious causative ocular or systemic conditions. ${ }^{5}$ POAG accounts for nearly threequarters (74\%) of all glaucoma cases. ${ }^{6,7}$ Various estimates and meta-analysis data show that estimated there could be 60,500,000 people with open-angle glaucoma (OAG) and angle-closure glaucoma (ACG) in 2010.6,8

\footnotetext{
Correspondence: Anadi Khatri

Department of Ophthalmology, VitreoRetina Fellow, Lumbini Eye Institute, PO Box No. 30, Siddhartha Nagar-3, Rupandehi - 3290I, Lumbini Zone, Nepal $\mathrm{Tel}+977$ I 4 II 2600

Fax +977984I76 7205

Email anadikc@gmail.com
}

submit your manuscript | www.dovepress.com
Dovepress
http://dx.doi.org// 0.2147/DMSO.SI60978




\section{Risk factors}

Hypertension (HTN) data on the relationship among HTN and intraocular pressure (IOP) are consistent across examination. This relation between POAG and blood pressure (BP) is unpredictable and inadequately understood. A few large-scale epidemiologic studies have investigated this relationship depicting conflicting reports. A few investigations have concluded that there is a low risk of glaucoma in individuals with elevated $\mathrm{BP}{ }^{9}$, whereas others reported significant associations between high systemic BP and POAG using cross-sectional data. ${ }^{10-13}$

\section{Diabetes mellitus (DM)}

$\mathrm{DM}$ and POAG are thought to have a direct relationship. Several theories on relation among DM and POAG have been proposed. The presence of long-standing hyperglycemia along with dyslipidemia may increase the danger of neuronal damage from oxidative stress. ${ }^{14}$ Various investigations have likewise demonstrated that diabetic eyes have a diminished ability to autoregulate blood flow and exhibit diminished retinal blood flow. ${ }^{15}$ Ciccone et a ${ }^{16}$ have described the effect of elevated sugar levels or insulin resistance in pre-diabetic patients with a strong history of DM in the family. Various biochemical pathways and cascades are thought to be activated causing endothelial dysfunction - ultimately leading to dysregulated vascular flow.

\section{Patients and methods}

This study is a prospective review of patients recruited from glaucoma clinic. Patients were eligible if they had a working diagnosis of POAG from their treating ophthalmologist with systemic illness such as HTN, DM - with or without medications, since they represent the major fraction of the study. Patients having a narrow angle in either eye or with PACG or any history of intraocular surgery (eg, vitreo-retinal procedures, glaucoma filtration surgeries), with secondary open-angle-closure glaucoma, inflammatory glaucoma, acute congestive glaucoma, and optic disc anomalies were excluded from the study.

Full threshold, Swedish Interactive Threshold Algorithm (SITA) standard, and SITA fast fields were accepted, with the majority of fields being SITA standard. Visual fields were manually screened by the author and any fields with an obvious neurological scotoma were also excluded. The data from both the subject's right and left eye were used if they individually satisfied the inclusion and exclusion criteria.
For every eligible patient, clinical evaluation was conducted were recorded in a database. Information collected includes the subject's age, sex, refraction, IOP (measured with Goldmann tonometry), and central corneal thickness. Furthermore, the medical, ocular, surgical, and medication histories of the subjects were obtained from patient files and recorded. Medical conditions were confirmed usually via correspondence from general practitioners, optometrist, or previous treating ophthalmologists.

The presumed risk factors include HTN, DM, or both. Severity on the basis of cup-disc ratio (CDR), disc hemorrhages, neuroretinal rim changes and Humphrey Visual Field Analysis Score (Parrish-Anderson [HPA] $)^{17}$ and Speath Field Damage likelihood score staging systems ${ }^{18}$ was done.

\section{Data processing and analysis}

Preformed proforma designed for this study was used to record the relevant history and clinical findings. Data were analyzed using SPSS 20 software (IBM Corporation, Armonk, NY, USA) after matching age, sex, and duration of the POAG/HTN/DM among the participants.

\section{Ethical clearance}

The research was approved by the ethics committee and the institutional review board of Institute of Medicine, Nepal, and has adhered to the tenets of the Declaration of Helsinki. Written informed consent was provided by the patients or their parents or legal guardian if the patients were under the age of 18 years.

\section{Results}

Detailed ophthalmic examination, including glaucoma workup was performed in 442 eyes of all 221 POAG patients.

Table 1 describes the demographic characteristics according to age and sex of all participants during the study period. In this study, a total of 221 cases of POAG were included.

Table I Age and sex distribution of POAG

\begin{tabular}{|c|c|c|c|}
\hline \multirow[t]{2}{*}{ Age, years } & \multicolumn{2}{|l|}{ Sex } & \multirow[t]{2}{*}{ Total (\%) } \\
\hline & Male & Female & \\
\hline $1 I-20$ & 2 & 4 & $6(2.7)$ \\
\hline $21-30$ & 9 & 3 & $12(5.4)$ \\
\hline $31-40$ & II & 15 & $26(11.7)$ \\
\hline $4 I-50$ & 14 & 21 & $35(15.8)$ \\
\hline $51-60$ & 31 & 22 & $53(23.9)$ \\
\hline $6 I-70$ & 25 & 26 & $5 I(23.1)$ \\
\hline $7 \mid-80$ & 15 & 22 & $37(16.7)$ \\
\hline $81-90$ & 0 & I & I (0.4) \\
\hline Total (\%) & $107(48.1)$ & $114(5 \mid .9)$ & $221(100)$ \\
\hline
\end{tabular}

Abbreviation: POAG, primary open-angle glaucoma. 


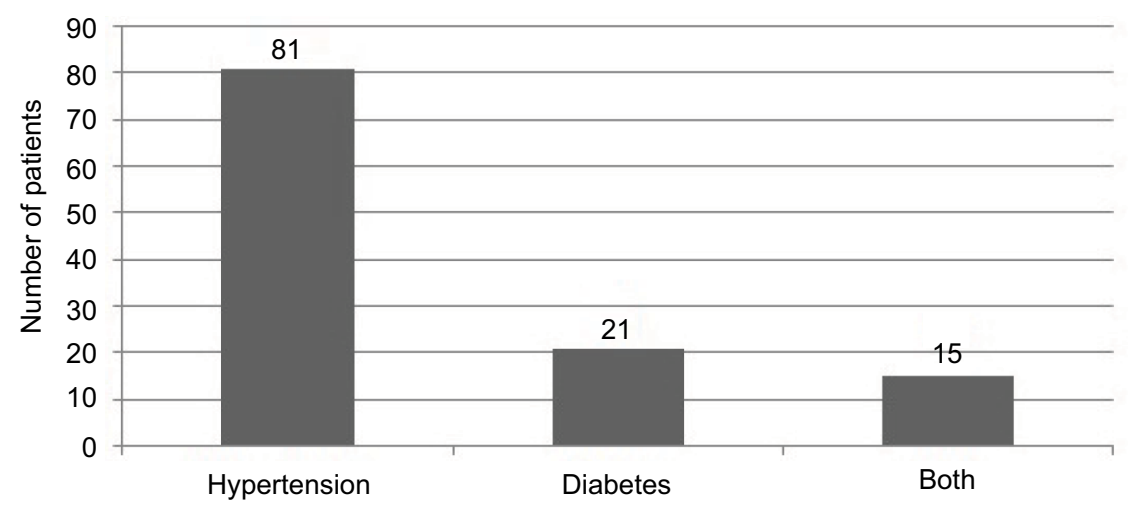

Figure I POAG patients with hypertension and diabetes.

Abbreviation: POAG, primary open-angle glaucoma.

In this study, there were 81 (36\%) participants with HTN, 21 (9.5\%) with DM, and 15 (6.8\%) with both HTN and DM (Figure 1). We analyzed these groups differently as a single and combined risk factor for severity, comparing it with the patients with POAG without either of the conditions.

The mean IOP (Table 2) in 2 groups at CI of $95 \%$ was comparable while the mean visual field defect (VFD) (Table 2) of the participants with HTN had tendency of being categorized under moderate VFD, in contrast, to mean VFD among participants without HTN, which has tendency of categorizing them under mild VFD. The CDR (Table 2) of the patients with HTN was also comparatively larger than the participants without HTN at CI of $95 \%$.

The comparison shows that the participants with HTN have higher chances of having severe VFD compared with the participants without HTN (odds ratio [OR] 2.75, 95\% CI: 1.51 to $5.00, p=0.001$; Table 3).

\section{Severity of POAG in patients with DM}

Similarly, for DM, there were $21(9.5 \%)$ participants with DM and 15 (6.8\%) with both HTN and DM.

Table 2 Ocular findings of patients of POAG with and without HTN

\begin{tabular}{llll}
\hline & & $\begin{array}{l}\text { Patients with } \\
\text { HTN }\end{array}$ & $\begin{array}{l}\text { Patients } \\
\text { without HTN }\end{array}$ \\
\hline IOP & Mean & 15.0 & 15.7 \\
& $95 \% \mathrm{Cl}$ for mean, $p<0.05$ & 14.2 to 15.9 & 14.9 to 16.5 \\
HVFA & Mean & -8.39 & -4.85 \\
& $95 \% \mathrm{Cl}$ for mean $p<0.05$ & $-1 \mathrm{I} . \mathrm{I}$ to -5.64 & -5.83 to -3.86 \\
CDR & Mean & $0.7 \mathrm{I}$ & $0.6 \mathrm{I}$ \\
& $95 \% \mathrm{Cl}$ for mean $p<0.05$ & 0.62 to $0.8 \mathrm{I}$ & 0.58 to 0.65 \\
\hline
\end{tabular}

Abbreviations: CDR, cup-disc ratio; HTN, hypertension; HVFA, humphrey visual field analysis; IOP, intraocular pressure; POAG, primary open-angle glaucoma.
Table 3 Severity of VFD in relation to HTN

\begin{tabular}{lllll}
\hline & & $\begin{array}{l}\text { Moderatel } \\
\text { severe (\%) }\end{array}$ & Mild (\%) & $\begin{array}{l}\text { Total } \\
\text { (\%) }\end{array}$ \\
\hline HTN & Yes & $48(25.9)$ & $33(17.8)$ & $81(43.7)$ \\
& No & $36(19.5)$ & $68(36.8)$ & $104(56.3)$ \\
Total & & $84(45.4)$ & $101(54.6)$ & $185(100)$ \\
\hline Risk estimate & Value & 95\% Cl & \\
\cline { 2 - 4 } & & Lower & Upper \\
\hline $\begin{array}{l}\text { Odds ratio for severity } \\
\text { (HTN/without HTN) }\end{array}$ & 2.75 & I.5I & 5.00 \\
$\begin{array}{l}\text { Number of valid cases } \\
\text { Significance level }\end{array}$ & I85 & & \\
\hline
\end{tabular}

Abbreviations: HTN, hypertension; VFD, visual field defect.

The mean IOP in 2 groups at CI of $95 \%$ was comparable (Table 4) while the mean VFD of the participants with DM had a tendency of being categorized under moderate VFD, in contrast, to mean VFD among participants without DM, which has a tendency of categorizing them under mild VFD (Table 4). The CDR of the patients with DM was also comparatively larger than the participants without DM at CI of 95\% (Table 4).

The comparison shows that the participants with DM have higher chances of having severe VFD compared with the participants without DM (OR 4.72, 95\% CI: 1.69 to 13.2 , $p=0.0031$; Table 5).

\section{Severity of POAG in patients with HTN and DM}

In this study, 15 (6.8\%) of the participants had both HTN and DM. We analyzed this group differently - a combined risk factor for severity of POAG. The mean IOP and CDR in 2 groups at $\mathrm{CI}$ of $95 \%$ were comparable (Table 5), while the mean VFD of the participants with DM and HTN had 
Table 4 Ocular findings of patients of POAG with and without DM

\begin{tabular}{llll}
\hline & & $\begin{array}{l}\text { Patients with } \\
\text { DM }\end{array}$ & $\begin{array}{l}\text { Patients without } \\
\text { DM }\end{array}$ \\
\hline IOP & Mean & 16.3 & 15.7 \\
& $95 \% \mathrm{Cl}$ for mean $p<0.05$ & 12.2 to 20.4 & 14.9 to 16.5 \\
HVFA & $95 \% \mathrm{Cl}$ for mean $p<0.05$ & -13.4 to -3.64 & -5.83 to -3.86 \\
CDR & Mean & 0.74 & 0.61 \\
& $95 \% \mathrm{Cl}$ for mean $p<0.05$ & 0.66 to 0.82 & 0.58 to 0.65 \\
\hline
\end{tabular}

Abbreviations: CDR, cup-disc ratio; DM, diabetes mellitus; HVFA, Humphrey visual field analysis; IOP, intraocular pressure; POAG, primary open-angle glaucoma.

Table 5 Severity of VFD in relation to diabetes

\begin{tabular}{|c|c|c|c|c|}
\hline & & $\begin{array}{l}\text { Moderate/severe } \\
\text { (\%) }\end{array}$ & Mild (\%) & Total (\%) \\
\hline \multirow[t]{2}{*}{ Diabetes } & Yes & $15(12.0)$ & $6(4.8)$ & $21(16.8)$ \\
\hline & No & $36(28.8)$ & $68(54.4)$ & $104(83.2)$ \\
\hline \multicolumn{2}{|l|}{ Total } & $51(40.8)$ & $74(59.2)$ & $125(100)$ \\
\hline \multicolumn{3}{|c|}{ Risk estimate } & \multicolumn{2}{|l|}{ Value } \\
\hline \multicolumn{3}{|c|}{ Odds ratio for severity (diabetes yes/no) } & \multicolumn{2}{|c|}{$4.72(95 \% \mathrm{Cl} \mathrm{I} .69$ to 13.2$)$} \\
\hline \multicolumn{3}{|c|}{ Number of valid cases } & \multicolumn{2}{|l|}{125} \\
\hline \multicolumn{3}{|c|}{ Significance level } & \multicolumn{2}{|l|}{$p=0.0031$} \\
\hline
\end{tabular}

Abbreviation: VFD, visual field defect.

tendency of being categorized under moderate VFD, in contrast, to mean VFD among participants without DM and HTN, which has tendency of categorizing them under mild VFD (Table 6).

The comparison shows that the participants with DM and HTN have higher chances of having severe VFD compared with the participants without DM (OR 19.9, 95\% CI: 2.52 to $156.8, p=0.0046$; Table 7).

\section{Discussion}

Among vascular factors, it has been long postulated that systemic HTN may cause increases in IOP mainly via overproduction from ciliary body or impaired outflow of aqueous humor. ${ }^{19}$ However, this relationship remains inconclusive and under debate. While some studies highlight that systemic HTN is a risk factor for glaucoma, ${ }^{10,20}$ other studies indicate that low systemic BP is more dangerous and poses a serious risk for the development and progression of glaucoma. In this study, 81 (36\%) participants had HTN. This was comparable with a study done by Garg et $\mathrm{al}^{21}$ where HTN was seen in $35.1 \%$ of their participants.

This study found that the mean IOP in patients with HTN was 15.04 (95\% CI: 14.2 to $15.9, p<0.05)$, mean VFD of -8.39 ( $95 \%$ CI: -11.1 to $-5.64, p<0.05$ ), and mean CDR of
Table 6 Ocular findings of patients of POAG with HTN and DM and without HTN and DM

\begin{tabular}{llll}
\hline & & $\begin{array}{l}\text { Patients with } \\
\text { HTN and DM }\end{array}$ & $\begin{array}{l}\text { Patients without } \\
\text { HTN and DM }\end{array}$ \\
\hline IOP & Mean & 16.0 & 15.7 \\
& $95 \% \mathrm{Cl}$ for mean $p<0.05$ & 13.9 to 18.0 & 14.9 to 16.5 \\
HVFA & Mean & -9.08 & -4.85 \\
& $95 \% \mathrm{Cl}$ for mean $p<0.05$ & -16.9 to -1.27 & -5.83 to -3.86 \\
CDR & Mean & 0.68 & 0.61 \\
& $95 \% \mathrm{Cl}$ for mean $p<0.05$ & 0.57 to 0.79 & 0.58 to 0.65 \\
\hline
\end{tabular}

Abbreviations: CDR, cup-disc ratio; DM, diabetes mellitus; HTN, hypertension; HVFA, Humphrey visual field analysis; IOP, intraocular pressure; POAG, primary open-angle glaucoma.

Table 7 Severity of VFD in relation to DM and HTN

\begin{tabular}{|c|c|c|c|c|}
\hline & & $\begin{array}{l}\text { Moderatel } \\
\text { severe (\%) }\end{array}$ & Mild (\%) & Total (\%) \\
\hline \multirow{2}{*}{$\begin{array}{l}\mathrm{HTN} \text { and } \\
\text { diabetes }\end{array}$} & Yes & $14(11.8)$ & $\mathrm{I}(0.8)$ & $15(12.6$ \\
\hline & No & $43(36.1)$ & $61(5 I .3)$ & $104(87.4)$ \\
\hline \multicolumn{2}{|l|}{ Total } & $57(47.9)$ & $62(52.1)$ & $119(100)$ \\
\hline \multicolumn{4}{|c|}{ Odds ratio (Severity with HTN and } & 19.9 \\
\hline \multicolumn{5}{|c|}{ DM/without $\mathrm{HTN}$ and DM) } \\
\hline \multicolumn{4}{|c|}{$95 \% \mathrm{Cl}$} & 2.52 to 156.8 \\
\hline \multicolumn{4}{|l|}{ z statistic } & 2.84 \\
\hline \multicolumn{4}{|c|}{ Significance level } & $p=0.0046$ \\
\hline
\end{tabular}

Abbreviations: DM, diabetes mellitus; HTN, hypertension; VFD, visual field defect.

0.71 ( $95 \%$ CI: 0.62 to $0.81, p<0.05$ ) in comparison with the patient without HTN who had mean IOP of 15.74 (95\% CI: 14.9 to $16.5, p<0.05$ ), mean VFD of -4.85 ( $95 \%$ CI: -5.83 to -3.86$)$, and mean CDR of 0.61 (95\% CI: 0.58 to 0.64 , $p<0.05)$. The mean IOP in 2 groups at $95 \%$ CI was comparable, while the mean VFD of the participants with HTN had a tendency of being categorized under moderate VFD, in contrast, to mean VFD among participants without HTN, which has a tendency of categorizing them under mild VFD. The CDR of the patients with HTN was also comparatively larger than the participants without HTN at CI of 95\%.

This study compared the severity of VFD among the POAG participants with and without HTN. The results showed that participants with HTN had OR 2.75 (95\% CI: 1.51 to $5.00, p=0.001$ ) of having severe visual field changes in comparison with the participant group without HTN.

The inclusion criteria for our participants were diagnosed case for HTN for at least 5 years and under medication. Earlier it was hypothesized that elevated BP might be protective against $\mathrm{POAG}$, but $\mathrm{He}$ et $\mathrm{al}^{22}$ reported that it was only an acute BP elevation, which makes retinal function and blood flow less susceptible to IOP. The improved ocular 
perfusion pressure to compensate for the acute rise in IOP is compromised after 4 weeks of HTN. Chan et $\mathrm{al}^{23}$ also reported that patients with cardiovascular disease were 2.33 times more likely to develop rapidly progressive glaucoma disease despite significantly lower mean and baseline IOPs.

DM is a serious and increasingly prevalent health issue worldwide due to an aging population and lifestyle changes. The prevalence of DM worldwide was estimated to be $2.8 \%$ in 2000 and is forecasted to be $4.4 \%$ in $2030 .{ }^{24}$ Some studies also found that DM has a strong link with $\mathrm{POAG}^{25,26}$ This relationship, however, still remains controversial. ${ }^{27,28}$

We compared patients with DM with patients without DM in this study. There were 21 (9.5\%) participants with DM. We found that the mean IOP in patients with DM was 16.3 (95\% CI: 12.2 to $20.4, p<0.05)$, mean VFD of -8.52 (95\% CI: -13.4 to $-3.64, p<0.05)$, and mean CDR of 0.74 (95\% CI: 0.66 to $-0.82, p<0.05)$. In comparison, the patient without DM had a mean IOP of 15.7 (95\% CI: 14.9 to $16.5, p<0.05)$, mean VFD of -4.85 ( $95 \%$ CI: -5.83 to $-3.86, p<0.05$ ), and mean CDR of 0.61 ( $95 \%$ CI: 0.58 to $0.65 p<0.05$ ), which were of significant statistical value to show that POAG was more severe among the diabetic group compared with that of the non-diabetic group.

This study also showed that DM had higher chances of having severe VFD compared with the participants without DM (OR 4.72, 95\% CI: 1.69 to $13.2, p=0.0031$ ). Much research has been done to see if there is an association between POAG and DM. In one study done by ShakyaViadya et al, ${ }^{29}$ they reported overall risk of a diabetic patient developing POAG increasing by 3.50 fold when compared with patients without diabetes.

Blue Mountains Eye Study ${ }^{30}$ provided crucial data of an entire population who underwent a detailed eye examination to establish a diagnosis of glaucoma or ocular HTN. The OR for glaucoma in diabetic patients compared with those without DM was 2.12 (95\% CI: 1.18 to 3.79). This was one of the first studies to establish a relationship between glaucoma and DM. The Baltimore Eye Study, ${ }^{28}$ which was conducted similar to the Blue Mountains Eye Study, also reported age-race adjusted OR of 1.03 (95\% CI: 0.85 to 1.25 ). But neither study describes or correlates if the severity of POAG is more with DM.

However, Toda and Nakanishi-Toda ${ }^{31}$ reported about a direct relationship between DM and POAG, which could help support our result. A few theories on relation among DM and POAG have been proposed. There is a developing assortment of confirmation that long-standing hyperglycemia, alongside lipid abnormalities, may increase the danger of neuronal damage from oxidative stress. ${ }^{32}$ Data from various laboratories have provided strong evidence for such an association. ${ }^{33}$
Another theory discusses that diabetic eyes have a dysfunctional autoregulation of blood flow hence causing decreased blood flow in the retina. ${ }^{34}$ This creates an environment of relative hypoxia - causing overexpression of hypoxiainducible factor-1 alpha (HIF-1 $\alpha$ ). ${ }^{35}$ It is now known that there is an increase in levels of HIF-1 $\alpha$ in ganglion cells of the retina and in the optic nerve head of human glaucomatous eyes. ${ }^{36}$ Ciccone et al ${ }^{16}$ have further described regarding the endothelial dysfunction due to activation of various cascades, which may further catalyze this vicious cycle.

Another theory postulates that in diabetic eyes, there is remodeling of the connective tissue of the optic nerve head. This might reduce compliance at the trabecular meshwork and also in the lamina cribrosa, resulting in increased IOP and elevated mechanical stress on the optic nerve head. ${ }^{37}$ Research has shown that DM can deregulate connective tissue remodeling and amplify these biomechanical changes. ${ }^{38}$ A systematic review and meta-analysis by Zhoum et $\mathrm{l}^{39}$ have also concluded that although the exact mechanism of how the DM and POAG is still under debate, their meta-analysis results show a significant association between DM and the risk of POAG. Patients with DM had about 1.4-fold increased risk of developing POAG in cohort studies while the casecontrol studies had nearly $49 \%$ increased odds of developing POAG compared with individuals without DM.

In the final part of this study, we compared patients with DM and HTN with participants without DM and HTN . There were $15(6.8 \%)$ participants in this group. This study found that the mean IOP in patients with both DM and HTN was 16.0 (95\% CI: 13.9 to $18.0, p<0.05$ ), mean VFD of -9.08 (95\% CI: -16.9 to $-1.27 p<0.05$ ), and mean CDR of 0.68 ( $95 \%$ CI: 0.571 to $0.785, p<0.05$ ). In comparison, the patient without DM and HTN had a mean IOP of 15.7 (95\% CI: 14.9 to $16.5, p<0.05)$, mean VFD of -4.85 (95\% CI: -5.83 to $-3.86, p<0.05$ ), and mean CDR of 0.61 (95\% CI: 0.58 to $0.65, p<0.05)$. The comparison shows that the participants with DM and HTN have higher chances of having severe VFD compared with the participants without DM (OR 19.9, 95\% CI: 2.52 to $156.8, p=0.0046$ ).

In a study done by Shakya-Vaidya et al, ${ }^{29}$ a strong association between POAG and DM (OR 3.15) was demonstrated. They concluded that their results suggest that POAG associates positively with HTN and DM in all ethnic groups. Newman-Casey et a ${ }^{40}$ - reported in one their study with 2,182,315 enrollees who met the inclusion criteria, 55,090 (2.5\%) had OAG. After adjustment for confounding factors, those with DM (hazard ratio [HR] $=1.35$, [95\% CI: 1.21 to 1.50]) or HTN (HR=1.17, [95\% CI 1.13 to 1.22$]$ ) alone or 
in combination ( $\mathrm{HR}=1.48$, [95\% CI 1.39 to 1.58$]$ ) had an increased hazard of developing OAG relative to persons with neither of these conditions. They also reported that people with DM alone had a 35\% increased risk of developing OAG and those with HTN alone had a $17 \%$ increased risk. For people with both DM and HTN, there was a $48 \%$ increased risk of developing OAG.

This shows a strong link of development of POAG among the patients with the various vascular conditions. This study has evaluated for severity of POAG among patients in similar groups as theirs. Although they have not reported on severity, an assumption might be made based on their study that - the association of these vascular phenomena on increasing the risk of developing POAG in the first place might also have a vital role to play in progression and severity of the disease as found in this study.

\section{Conclusion}

We found that patients with HTN and DM or both had a more severe form of POAG when compared with the participants without these risk factors. Patients with these risk factors could represent "high-risk patients" and should be identified and be explained about the condition. A good documentation of the previous investigation is a must to analyze the rate of progression - and modification in the treatment may be required accordingly. The patients should be made aware of the various risk factors they may have, which may alter the course of the disease. They should be advised/recommended regarding the requirement of evaluations on a more frequent basis to access the progression/ severity of POAG.

\section{Disclosure}

The authors report no conflicts of interest in this work.

\section{References}

1. Resnikoff S, Pascolini D, Etya'ale D, et al. Global data on visual impairment in the year 2002. Bull World Health Organ. 2004;82(11):844-851.

2. Goldberg I, Graham SL, Healey PR. Primary open-angle glaucoma. Med J Australia. 2002;177(10):535-536.

3. Palimkar A, Khandekar R, Venkataraman V. Prevalence and distribution of glaucoma in central India (Glaucoma Survey 2001). Indian J Ophthalmol. 2008;56(1):57-62.

4. Hitchings RA. Glaucoma screening. Br J Ophthalmol. 1993;77:326.

5. Stamper RL, Lieberman MF, Drake MV. CHAPTER 17 - Primary open angle glaucoma. In: Becker-Shaffer's Diagnosis and Therapy of the Glaucomas (8th Edition). [Internet]. Edinburgh: Mosby; 2009:239-265. Available from: https://www.sciencedirect.com/science/article/pii/ B9780323023948000176. Accessed September 13, 2017.

6. Quigley HA, Broman AT. The number of people with glaucoma worldwide in 2010 and 2020. Br J Ophthalmol. 2006;90(3):262-267.
7. World Health Organization. Visual impairment and blindness: Fact Sheet No 282. 2014. Available from: http://www.who.int/en/news-room/factsheets/detail/blindness-and-visual-impairment. Accessed September, 2014.

8. Tham YC, Li X, Wong TY, Quigley HA, Aung T, Cheng CY. Global prevalence of glaucoma and projections of glaucoma burden through 2040: a systematic review and meta-analysis. Ophthalmology. 2014; 121(11):2081-2090.

9. Leske MC, Heijl A, Hyman L, Bengtsson B, Dong L, Yang Z; EMGT Group. Predictors of long-term progression in the early manifest glaucoma trial. Ophthalmology. 2007;114(11):1965-1972.

10. Bonomi L, Marchini G, Marraffa M, Bernardi P, Morbio R, Varotto A. Vascular risk factors for primary open angle glaucoma: the Egna-Neumarkt Study. Ophthalmology. 2000;107(7):1287-1293.

11. Dielemans I, Vingerling JR, Wolfs RC, Hofman A, Grobbee DE, de Jong PT. The prevalence of primary openangle glaucoma in a populationbased study in the Netherlands. The Rotterdam Study. Ophthalmology. 1994;101(11):1851-1855.

12. Dielemans I, Vingerling JR, Algra D, Hofman A, Grobbee DE, de Jong PT. Primary open-angle glaucoma, intraocular pressure, and systemic blood pressure in the general elderly population. The Rotterdam Study. Ophthalmology. 1995;102(1):54-60.

13. Memarzadeh F, Ying-Lai M, Chung J, Azen SP, Varma R; Los Angeles Latino Eye Study Group. Blood pressure, perfusion pressure, and openangle glaucoma: the Los Angeles Latino Eye Study. Invest Ophthalmol Vis Sci. 2010;51(6):2872-2877.

14. Kong GY, Van Bergen NJ, Trounce IA, Crowston JG. Mitochondrial dysfunction and glaucoma. J Glaucoma. 2009;18(2):93-100.

15. Clermont AC, Bursell SE. Retinal blood flow in diabetes. Microcirculation. 2007;14(1):49-61.

16. Ciccone MM, Scicchitano P, Cameli M, et al. Endothelial function in pre-diabetes, diabetes and diabetic cardiomyopathy: a review. J Diabetes Metab. 2014;5:364.

17. Hodapp E, Parrish RK II, Anderson DR. Clinical Decisions in Glaucoma. St. Louis, MO, USA: Mosby-Year Book, Inc; 1993.

18. Henderer JD, Altangerel U, Magacho L, et al. A new visual field staging system for glaucoma: observer agreement compared to three other systems. Paper presented at: The 13th Annual Meeting of the AGS; March 8, 2003; San Francisco, CA, USA.

19. Caprioli J, Coleman AL; Blood Flow in Glaucoma Discussion. Blood pressure, perfusion pressure, and glaucoma. Am J Ophthalmol. 2010;149(5):704-712.

20. Orzalesi N, Rossetti L, Omboni S; OPTIME Study Group (Osservatorio sulla Patologia glaucomatosa, Indagine Medico Epidemiologica); CONPROSO (Collegio Nazionale dei Professori Ordinari di Scienze Oftalmologiche). Vascular risk factors in glaucoma: the results of a national survey. Graefes Arch Clin Exp Ophthalmol. 2007;245(6): 795-802.

21. Garg P, Singh L, Malhotra R, Lisa M. A study on systemic risk factors for primary open angle glaucoma. Int J Life Sci Pharma Rev. 2014;4(2):ISSN 2250-0480.

22. He Z, Vingrys AJ, Armitage JA, Nguyen CT, Bui BV. Chronic hypertension increases susceptibility to acute IOP challenge in rats. Invest Ophthalmol Vis Sci. 2014;55(12):7888-7895.

23. Chan TCW, Bala C, Siu A, Wan F, White A. Risk factors for rapid glaucoma disease progression. Am J Ophthalmol. Epub 2017 Jun 15.

24. Wild S, Roglic G, Green A, Sicree R, King H. Global prevalence of diabetes: estimates for the year 2000 and projections for 2030. Diabetes Care. 2004;27(5):1047-1053.

25. Pasquale LR, Kang JH, Manson JE, Willett WC, Rosner BA, Hankinson SE. Prospective study of type 2 diabetes mellitus and risk of primary open-angle glaucoma in women. Ophthalmology. 2006;113(7):1081-1086.

26. Klein BE, Klein R, Jensen SC. Open-angle glaucoma and olderonset diabetes. The Beaver Dam Eye Study. Ophthalmology. 1994;101(7):1173-1177. 
27. de Voogd S, Ikram MK, Wolfs RC, et al. Is diabetes mellitus a risk factor for open-angle glaucoma? The Rotterdam Study. Ophthalmology. 2006;113(10):1827-1831.

28. Tielsch JM, Katz J, Quigley HA, Javitt JC, Sommer A. Diabetes, intraocular pressure, and primary open-angle glaucoma in the Baltimore Eye Survey. Ophthalmology. 1995;102(1):48-53.

29. Shakya-Vaidya S, Aryal UR, Upadhyay M, Krettek A. Do non-communicable diseases such as hypertension and diabetes associate with primary open-angle glaucoma? Insights from a case-control study in Nepal. Glob Health Action. 2013;6:22636.

30. Mitchell P, Smith W, Chey T, Healey PR. Open-angle glaucoma and diabetes: the Blue Mountains Eye Study. Ophthalmology. 1997;104(4):712-718.

31. Toda N, Nakanishi-Toda M. Nitric oxide: ocular blood flow, glaucoma and diabetic retinopathy. Prog Retin Eye Res. 2007;26(3):205-238.

32. Kong GY, Van Bergen NJ, Trounce IA, Crowston JG. Mitochondrial dysfunction and glaucoma. J Glaucoma. 2009;18(2):93-100.

33. Neufeld AH, Hernandez MR, Gonzalez M. Nitric oxide synthase in the human glaucomatous optic nerve head. Arch Ophthalmol. 1997;115(4):497-503.
34. Clermont AC, Bursell SE. Retinal blood flow in diabetes. Microcirculation. 2007;14(1):49-61.

35. Arjamaa O, Nikinmaa M. Oxygen-dependent diseases in the retina: role of hypoxia-inducible factors. Exp Eye Res. 2006;83(3): $473-483$.

36. Tezel G, Wax MB. Hypoxia-inducible factor 1alpha in the glaucomatous retina and optic nerve head. Arch Ophthalmol. 2004;122(9): $1348-1356$

37. Roberts MD, Grau V, Grimm J, et al. Remodeling of the connective tissue microarchitecture of the lamina cribrosa in early experimental glaucoma. Invest Ophthalmol Vis Sci. 2009;50(2):681-690.

38. Francis-Sedlak ME, Uriel S, Larson JC, Greisler HP, Venerus DC, Brey EM. Characterization of type I collagen gels modified by glycation. Biomaterials. 2009;30(9):1851-1856.

39. Zhou M, Wang W, Huang W, Zhang X. Diabetes mellitus as a risk factor for open-angle glaucoma: a systematic review and meta-analysis. PLoS ONE. 2014;9(8):e102972.

40. Newman-Casey PA, Talwar N, Nan B, Musch DC, Stein JD. The relationship between components of metabolic syndrome and open-angle glaucoma. Ophthalmology. 2011;118(7):1318-1326.
Diabetes, Metabolic Syndrome and Obesity: Targets and Therapy is an international, peer-reviewed open-access journal committed to the rapid publication of the latest laboratory and clinical findings in the fields of diabetes, metabolic syndrome and obesity research. Original research, review, case reports, hypothesis formation, expert opinion and commentaries are all considered for publication. The manuscript management system is completely online and includes a very quick and fair peer-review system, which is all easy to use. Visit http://www.dovepress.com/testimonials.php to read real quotes from published authors.

Submit your manuscript here: https://www.dovepress.com/diabetes-metabolic-syndrome-and-obesity-targets-and-therapy-journal 